\title{
The use of employee participation in the USA and Spanish companies*
}

\author{
Juan A. Marin-Garcia ${ }^{1 \dagger}$, Tomas Bonavia ${ }^{2}$, Cristóbal Miralles ${ }^{1}$ \\ 1 Universidad Politcnica de Valencia \\ 2 Universidad de Valencia
}

(Received October 6 2007, Accepted December 28 2007)

\begin{abstract}
This article presents a description of employee participation in Spain. The number of published papers in English about Spain regarding this subject is very low, and even lower by Spanish authors. In short, we can say that there is hardly any knowledge regarding employee participation in Spain in both the European and American settings. This paper summarized the results of a research project we carried out whose objective was to compare employee participation using samples from large American and Spanish companies following the works of Edward E. Lawler and his team. Our aim is to have professionals and researchers throughout the world better understand the actual situation in our country.
\end{abstract}

Keywords: participation in decision-making (PDM), financial/economic participation, direct and indirect participation

\section{Introduction}

There is considerable research that attempts to show what effects greater employee participation has on their satisfaction and productivity. Nevertheless, one of the important conclusions of the EPOC study ${ }^{[3]}$ is that there is still an important disparity between the rhetoric and the actual situation; between what is supposed and what is really happening. According to Sisson ${ }^{[34]}$, while everyone seems to assume that the development and implementation of new forms of work organization is inevitable, the truth is that even the most basic practices associated with these forms are absent in the majority in the EU (European Union) workplaces. Therefore, research is at present, and above all in Spain, at a point which it would be convenient to take a step back and ask again this question: How can we describe the situation in our country in relation to other countries in order to estimate how extensively employee participation systems are used and how many workers are really affected by them?

\section{Theoretical framework}

Extensive research has been carried out related to worker participation and cross-cultural differences between countries and regions. For an extensive overview of the existing literature on this particular area, the following is highly recommended: International Yearbook of Organizational Democracy ${ }^{[7,35,37]}$; The International Handbook of Participation in Organizations ${ }^{[23,31]}$; results from the International Research Group ${ }^{[13,14]}$; different research projects from the European Foundation for the Improvement of Living and Working Conditions since 1975; as well as the OECD reports ${ }^{[27,28]}$.

\footnotetext{
* We would like to thank the Foreign Language Co-ordination Office at the Polytechnic University of Valencia for their help in translating this article.

† E-mail address: jamarin@omp.upv.es.
} 
A large part of this research developed in the European setting focused on, especially in the beginning, the phenomenon of industrial democracy. In almost all of the cases the research left out comparisons with Spain. Spain was only mentioned when dealing with the well-known Mondragón Case ${ }^{[5,36]}$. An example that illustrates this is the $\operatorname{IDE}^{[13]}$ which was an ambitious research project about industrial democracy carried out by different European countries, although unfortunately did not include our own. Likewise, the few studies which have focused on participative management techniques in Europe have also left out the situation which exists in our country. A recent example is the work of the $\operatorname{IPSE}^{[21]}$ about financial participation in the United Kingdom (UK), France, Germany and Italy. Thus, diverse authors explicitly recognize an almost complete lack of systematic knowledge about the actual functioning of the participation systems about $\operatorname{Spain}^{[22]}$. This situation can be generalized to the rest of Europe, except for UK and, in part, France and Germany. In contrast, both implementation and research on this matter in Japan and the United States began beforehand and have been developed much more extensively than in Europe which gives these countries a considerable advantage ${ }^{[33]}$.

In this context, we know of absolutely no study in which its explicit objective was the comparison of the situation in our country with that of the United States. In order to advance a better knowledge about this topic, the research that we have carried out compared employee participation using samples from large American and Spanish companies following the works of Lawler, Mohrman, and Benson ${ }^{[17]}$; Lawler, Mohrman, and Ledford $^{[18-20]}$. Two hypothesis were investigated:

- $H_{1}$. Workers involved in Participation in Decision Making will be higher in USA than in Spain, except for the Union-management committees (a clear example of indirect participation).

- $\mathrm{H}_{2}$. Workers covered by financial participation will be higher in USA than in Spain, except for fixed salary (the least participative scheme).

In relation to the hypothesis $1^{[32]}$, employee participation is defined in USA as an organizational process by which management shares influences on decision making with his/her subordinates, group or individually (direct participation). Whereas the West European approach emphasizes institutionalized participation of employee representatives in decisions that are relevant to labor-management relations (indirect participation). In the first comparative study published, which includes our country, Gill and Krieger ${ }^{[11]}$ carried out a far-reaching attitudinal survey with 7,326 people participating. This study was carried out in 1987-1988 in the then twelve member countries of the EU and was led by the European Foundation for the Improvement of Living and Work Conditions. At the time it was the only comparative study between all of the member countries of the EU and therefore the first one to include Spain. The study centered on various aspects of participation by employee representatives in new information technology. Spain had an intermediate position (together with Belgium, France, Germany and Italy) between those that promoted a greater participation from their union representatives to improve the quality of their products and services (as is the case in Denmark, The Netherlands, UK, Ireland and Greece), and those who did so the least (Luxembourg and Portugal). Nevertheless, when both the managers and the union representatives were asked what the future holds, in all of the countries they clearly stated their desire to increase this level of participation, albeit this desire was greater in the countries which already had a greater participation of its representatives in innovation technology matters.

Similar conclusions were reached in the praiseworthy research carried out by Herman Knudsen ${ }^{[22]}$ comparing four EU countries: Germany, UK, Spain and Denmark. The panorama that describes for our country is not very encouraging. There is hardly any mention of direct participation, which is practically non-existent. He focuses the analysis on the systems of worker representation within a context of union-management confrontation; a framework of conflicting classes as an essential characteristic of industrial relations. In the words of the author (Knudsen: 79-80): "compared to other national systems in Europe, the collaborationist elements of the Spanish system are relatively weak The participation of Spanish employees, then, has an overwhelmingly defensive and reactive character Because of this, participation has remained relatively insignificant as a mode of regulation".

With regard to hypothesis 2, Poutsma ${ }^{[30]}$ using a report previously known as PEPPER II (Promotion of Employee Participation in Profits and Enterprise Results) and the results of the study EPOC (Employee Direct Participation in Organizational Change), both of which were carried out in 1996 in 10 countries of the EU, advanced some conclusions on financial participation (for more information on the EPOC project, see, for example, [33, 34]. The first thing which was recognized was the significant lack of research on this 
topic as well as its scant implementation in Europe, with the exception of UK. The United Kingdom together with the United States are two of the countries which have developed most direct participation and financial participation. Additionally, the legal differences in this matter between the different European countries are also significant, with Spain being one of the countries with the least legal foundations. In fact, the countries with the greatest legal development, such as France or UK, have a substantial use and spread of financial participation schemes. Other factors which clearly have a positive influence are the size of the company, the use of a team-based workplace and being in the commercial sector. The largest companies in the commercial sector with the greatest development of the team-based workplace are those which have the greatest level of implementation of financial participation systems.

Summing up of this study, UK has substantial application of both types of financial schemes: profitsharing and share ownership. Spain has some share ownership (8\% of companies against $6 \%$ of profit-sharing only; $2 \%$ use both). In fact, our country is shown in logistic regression models as a factor with a significant negative effect in the use of profit-sharing schemes and with a positive effect in the event of share ownership. France promotes profit-sharing. The Netherlands and Sweden have developed relatively more direct participation schemes. Sweden has little share ownership. In all, as Poutsma ${ }^{[30]}$ states: "These country differences determine the existence of schemes to a large extent".

To sum up, as can be seen in these studies, standing out above all is the purely descriptive nature of these studies. They are fundamentally focused on finding the proportion of companies that use or do not use certain employee participation practices. Secondly, it has only been recently when we have had at our disposal data regarding our country ${ }^{[8]}$. However, these data focus on analyzing representative participation and the development of share ownership schemes which to a large extent are connected to the phenomenon of industrial democracy. There is hardly any material which describes what occurs in Spain regarding direct participation (with the exception of the EPOC project). Finally, it happens that these studies which report on whether a company has or has not implemented a participative technique can be very misleading because they do not indicate how many employees really have a greater level of participation.

Due to these reasons, we were encouraged to carry out this research. The work by Lawler and his team ${ }^{[17-20]}$ respond to these questions because, although they continue to be of a fundamentally descriptive nature, as in the rest of the studies considered, they allow us to more deeply understand what occurs with employee participation when taking into account not only which programs to implement or not, but also how many employees are truly affected directly from their implementation.)

\section{Methodology}

According to research carried out by Lawler ${ }^{[15,17]}$, as well as other authors such as Coye and Belohlav ${ }^{[6]}$ and Marchington, Wilkinson, Ackers and Goodman ${ }^{[24]}$, the employee involvement consists of four critical factors which were identified as: information sharing (degree of downward and upward flow of information), training (expertise and knowledge of specific operations and the organization in general), decision making (types of decisions and the areas in which decisions are made), and rewards (types of compensation used within the organization). We will not deal with the aspects relating to information sharing and employee training in order to focus on participation in decision making and financial participation in a broad sense, and therefore including reward systems. With the precise objective of gaining accuracy, we have opted for using throughout this article the term employee participation instead of employee involvement although this work is to a large extent based on the research carried out by Lawler; this is because we are not tackling other fundamental yet general elements of this concept such as information sharing and training. The comparison of American data with Spanish data has been possible thanks to the special cooperation with Professor Lawler and his team beginning in 1995 and ending with a memorandum of understanding signed in 1996.

The criterion for sample selection was the same used by Lawler, Mohrman, and Ledford ${ }^{[18-20]}$. The Spanish sample was based on the 2,500 largest Spanish companies in terms of turnover according to the 1997 database published by Fomento de la Produccin. We then obtained a probabilistic sample using numbers at random, resulting in a final sample of 861 companies to which questionnaires were sent. A total of 183 questionnaires were returned (21.3\%), 73 of which were incomplete and 110 answered correctly (12.8\%). 
The questionnaire included as variables a translation of questions included by Lawler and colleagues (see appendix). In order to achieve the equivalence of both instruments, the items were translated by an expert and back-translated again. Besides, some doubts with the translation of the concepts were resolved jointly with American researches. Each of the variables was measured using a 1-7 Likert scale with the following equivalencies: 1 ( $0 \%$ of employees are involved in each activity or program), 2 (1\%-20\% of employees are involved), 3 (21\%-40\%), 4 (41\%-60\%), 5 (61\%-80\%), 6 (81\%-99\%), 7 (100\% of employees are involved).

The questionnaires were sent to the human resources managers as the first choice. If this position did not exist, Chief Executive Officers (CEO) answered the questionnaire themselves or send to other managers. 63\% of the answers came from human resource managers, $15 \%$ from the CEO, and the other $22 \%$ were completed by a wide variety of senior executives. The chosen method as well as the distribution of the people who responded is comparable to the studies by Lawler and collaborators. Our study was carried out between June and September 1997 and the data requested was for that year.

The 110 replies as a whole would be representative if there was no bias between the group of companies that reply and those that don't, thus doing away with the criteria of random extraction. Summing up the analysis carried out, compared to the initial sample, there is no bias toward the group of companies that replied to our questionnaire for reasons of worker qualifications, profits, net added value per worker or geographical distribution. However, the replies reveal a certain bias towards larger companies and less sales per worker.

We should keep in mind that the above-mentioned studies, for example those by Lawler, all use the same procedure (with the exception of Knudsen ${ }^{[22]}$ which consisted of a theoretical analysis of the situation in each country) and that in all of them the sample is biased towards larger companies. Additionally, keeping in mind the normal rate of responses for mail-in questionnaires (for example, what occurred in the EPOC survey is paradigmatic - of the 5,000 workplaces in Spain to which the survey was sent, only $9 \%$ responded; and in the studies by Lawler, the rate of response fluctuated between $32 \%$ the first year to $15 \%$ in the last year), our sample has exactly the same tendency which appears in this type of study and may therefore be subject to similar criticism. Likewise, we do not have a way of estimating other types of biases which are more dangerous when interpreting the results. For example, respondents were more likely to be companies which have a higher level of implementation of participative procedures. This is a criticism which unfortunately can also be made about all of the other studies.

Summarizing, after studying the representativeness of the sample, we can state that the data collected sufficiently meet the minimum conditions for guaranteeing making conclusions, provided that we restrict ourselves in the interpretation to large companies of our country. This is precisely the sector in which the majority of the studies performed of this type in other countries are concentrated.

\section{Results}

To compare participation between Spain and the United States, we have drawn up two tables with the average percentage of workers involved by each participation program. Each table features the series of data available for the United States (USA87, USA90, USA93, USA96, USA99) and the data obtained for Spain (ESP97). The US data are from the Center of Effective Organizations ${ }^{[17-20]}$. In order to calculate these averages for the United States, we multiplied the percentage of companies which answer to each of the intervals on the Likert scale by the average value of that interval. We followed the same procedure for the Spanish data.

The first table summarizes participation in the decision making process. The Tab. 2 focuses on financial participation. For an exact definition of each program, see appendix.

For participation in decision making, American companies seem to have stabilized the use of individual suggestions systems, employee committees in strategy matters, quality circles and union-management committees. The former is used widely and affects a significant number of workers, the following two are used moderately, while the latter is used occasionally. The rest of the procedures have been implemented with more and more workers each year. Of these, the most widely used method by far is survey feedback.

In order to study the statistical significance of the differences in the level of use, we used a one-way ANOVA with a post hoc test by Least Square Distance $(\alpha=.05)$ between the Spanish data and each of the American series. In comparison with Spain, significant statistical differences appear in all of the programs 
Table 1. Workers involved in participation in decision making (Spain-USA).

\begin{tabular}{|c|c|c|c|c|c|c|}
\hline Program & USA87 & USA90 & USA93 & USA96 & USA99 & ESP97 \\
\hline Suggestion system & $49 \% * * *$ & $47 \% * * *$ & $41 \%$ & $41 \%$ & $42 \%$ & $31 \%$ \\
\hline Survey feedback & $31 \% * * *$ & $36 \% * * *$ & $51 \% * * *$ & $60 \% * * *$ & $63 \% * * *$ & $19 \%$ \\
\hline Job enrichment or redesign & $15 \% * * *$ & $17 \% * * *$ & $24 \%$ & $28 \%$ & $24 \%$ & $23 \%$ \\
\hline Quality circles & $15 \%$ *** & $18 \%$ *** & $19 \% * * *$ & $17 \%$ *** & $13 \%$ *** & $25 \%$ \\
\hline Other employee participation groups & $19 \% * *$ & $27 \%$ & $36 \% * *$ & $37 \% * * *$ & $33 \%$ & $27 \%$ \\
\hline Union-management committees & $7 \% * * *$ & $7 \% * * *$ & $10 \% * * *$ & $7 \% * * *$ & $6 \% * * *$ & $28 \%$ \\
\hline Self-managing work teams & $4 \%$ & $7 \%$ & $12 \%$ & $17 \% * * *$ & $17 \% * * *$ & $8 \%$ \\
\hline Minibusiness units & $4 \%$ & $5 \%$ & $12 \% * * *$ & $16 \% * * *$ & $15 \% * * *$ & $6 \%$ \\
\hline Employee committees in strategy matters & n.a. & n.a. & $13 \%$ & $14 \%$ & $15 \%$ & $9 \%$ \\
\hline Number of companies (N) & 323 & 313 & 279 & 212 & 143 & 105 \\
\hline
\end{tabular}

** Spain vs. USA significantly different at the .05 level; *** at the .01 level. "n.a." not available

except in the following: suggestion system, job enrichment or redesign, other employee participation groups, and employee committees in strategy matters; in all of these Spain has a lower level. In the rest of the programs the differences are even more evident, which means that a much lower number of workers are really affected by the introduction of these programs.

Special mention should be made of what seems to be occurring with the group suggestions systems. While in the United States the quality circles are showing a progressive decrease, thus increasing the importance of other types of groups, when the study was carried out in Spain there was a greater percentage of workers in quality circles than in the rest of the types of groups. On the other hand, the semi-autonomous groups and the mini business units companies show a moderate use in the United States, although the tendency is clearly to be on the increase. However, the level of use in Spain is very limited. Finally, in Spain, as we expected, union management committees and other instruments under the control of union organizations are more common.

On the other hand, upon observing in Tab. 2 the behavior of American companies for more than ten years, we can see that there is a group of financial participation programs whose use is stabilized (fixed salary) or has significantly decreased (employment security). They also show a certain stagnation of knowledge/skill based pay and profit sharing. The others are affecting the workers more and more over time.

Table 2. Workers covered by financial participation(Spain-USA).

\begin{tabular}{l|l|l|l|l|l|l}
\hline \multicolumn{1}{c|}{ Program } & USA87 & USA90 & USA93 & USA96 & USA99 & ESP97 \\
\hline Fixed salary & $39 \% * * *$ & $31 \% * * *$ & $38 \% * * *$ & $35 \% * * *$ & $37 \% * * *$ & $50 \%$ \\
\hline Knowledge/Skill-based pay & $11 \% * * *$ & $10 \% * * *$ & $16 \% * * *$ & $15 \% * * *$ & $14 \% * * *$ & $31 \%$ \\
\hline Individual incentives & $20 \% * *$ & $27 \%$ & $28 \%$ & $34 \% * *$ & $39 \% * * *$ & $26 \%$ \\
\hline Work group incentives & n.a. & $15 \%$ & $21 \%$ & $26 \%$ & $31 \% * * *$ & $21 \%$ \\
\hline Profit sharing & $35 \% * * *$ & $36 \% * * *$ & $37 \% * * *$ & $43 \% * * *$ & $40 \% * * *$ & $15 \%$ \\
\hline Gainsharing, Scanlon, & $6 \% * * *$ & $7 \% * * *$ & $12 \%$ & $13 \%$ & $17 \%$ & $14 \%$ \\
\hline Non-monetary recognition awards & n.a. & $48 \% * * *$ & $55 \% * * *$ & $59 \% * * *$ & $66 \% * * *$ & $19 \%$ \\
\hline Flexible benefits (cafeteria-style) & $23 \% * *$ & $36 \% * * *$ & $51 \% * * *$ & $51 \% * * *$ & $59 \% * * *$ & $10 \%$ \\
\hline Employment security & $34 \%$ & $26 \%$ & $19 \% * *$ & $16 \% * * *$ & $15 \% * * *$ & $29 \%$ \\
\hline Stock option plans & $45 \% * * *$ & $48 \% * * *$ & $52 \% * * *$ & $53 \% * * *$ & $53 \% * * *$ & $5 \%$ \\
\hline Number of companies (N) & 323 & 313 & 279 & 212 & 143 & 105 \\
\hline$* *$ Spain & &
\end{tabular}

** Spain vs. USA significantly different at the .05 level; *** at the .01 level. "n.a." not available

In comparing both countries, the percentage of employees who mainly receive a fixed salary affects about a third of the Americans studied (maintaining a relatively constant evolution throughout the series of years studied), while Spain reaches a figure of $50 \%$. With the passage of time, more and more salary complements have been used in both countries, although these have affected a greater proportion of American workers. The differences arrived at profit sharing are highly noteworthy: about three American employees participate in profit sharing for every one Spanish employee. Nevertheless, it is surprising that with respect to gainsharing 
by employee suggestions (Scanlon plans, Improshare plan, etc.), the percentage of employees affected in both countries is very close (as a matter of fact, this is the only variable in which there was no statistically significant differences).

Regarding the achievement of individual and group incentives, non-monetary compensation, flexible benefits (cafeteria-style) and stock option plans, the differences between both countries are very great and involvement is much greater for American employees. Only the forms of employee security (clauses in the contracts directed at avoiding the dismissal of the employee) seem to be more extensive in our country for large companies than in the United States where a clear backwards movement can be seen. Osterman ${ }^{[29]}$ was surprised by this fact, and time seems to have strengthened his views in the sense that we should be aware of the evolution of these practices of security in American companies because they would be able to bring about an important change in the employer-employee relationship, as is what seems to have happened. This could have very damaging effects on employees in times of economic uncertainty. Nevertheless, in Spain the importance of this measure is preserved, at least for now.

Commentary aside, skill-based pay is deserved, and although if in our country a very high score which is greater than that of the American sample was obtained, in our opinion this is due more to a bad interpretation of the question by the respondents than the actual situation. For example, if these results are contrasted with those obtained by the consultants Watson and Wyatt ${ }^{[38]}$ in the same year for our country, the percentage of affected workers is drastically reduced to $2 \%$, and reach $6 \%$ in the case of the managers. In all, we believe the respondents confused skill-based pay (new knowledge and skills which an employee continually gains to become more multi-faceted) with receiving a distinct salary according to the hierarchical position that the employee occupies or his/her seniority.

\section{Discussion and conclusions}

Different authors state that the practices which have had success in a specific cultural context, mainly Japanese and American, has been generalized to other very different contexts as in the case of Europe. This is precisely due to the necessity of improving the level of quality of the products and services with the objective of being more competitive ${ }^{[11,29]}$. This came about with the adoption of methods and philosophies such as Total Quality Management (TQM) and new Human Resource Management (HRM) practices, which began in the 1980s and became consolidated over time in very diverse countries.

However, as regards employee participation, the situation does not seem to be so clear. The studies carried out by the European Foundation ${ }^{[9,11,30,33,34]}$ as well as by Knudsen ${ }^{[22]}$ confirm that the national industrial relations structures and traditions (including regulation and bargaining patterns, and management styles) significantly affect the extent and intensity of participation.

Along these same lines, a report published by the European Commission ${ }^{[1,2]}$ has bearing: there is greater diversity than unity in the use of financial participation in the countries of the EU. This is a line of argument in which coincide previous studies prepared by the European Commission as well as other studies such as Gatley [10] or [12]. As Poutsma ${ }^{[30]}$ says: "The way in which organizations, and subsequent employment relationships, in a country are structured and managed is strongly influenced by national, specific social and cultural factors, so much so that one can identify 'societal patterns' of management and organizations".

Nevertheless, Lawler ${ }^{[15]}$ progressively expressed the opposite. In his opinion, a great amount of data is being accumulated which sustain that the companies in the United States and western Europe are heading towards a more participative focus. Globalization may be showing its first effects, above all in large companies which are obliged to compete in international markets. If certain practices are showing themselves to be useful in different contexts, what cultural idiosyncrasy gives the basis to argue that they should not be used? This is relevant if we are considering private companies in need of maximum efficiency. As Lawler ${ }^{[16]}$ points out, companies are seeing more and more that in order to compete in the current world economy it is necessary to use the most recent and refined approaches of organization and management. Furthermore, in the opinion of this author the participative approach is very consistent with the democratic values and respect for individual rights which are prevalent in the USA and Europe, and so the organizations which adopt them will have a 
clear competitive advantage. As a matter of fact, it is very possible that the participation of the employees constitutes a definite competitive advantage for American and European companies.

So then, what has the most influence in the business world? The cultural particularities of each country in which the organizations settle (united to their system of industrial relations, the structure of their institutions, their traditions, their laws and their political context)? Or the need of the companies to survive in an environment which is getting more and more competitive, turbulent and global?

The evidence presented in this article endorses the idea that clear national tendencies exist from one country to the other. Spain shows differences with respect to its European neighbors as well as its relationship to the United States; these differences are very pronounced in both cases. The comparative studies carried out in Europe offer an image that is not totally adjusted to the situation in our country. Of the studies that were revised, we can conclude that Spain has an intermediate position in comparison with European countries regarding indirect participation ${ }^{[11]}$ in a general context of confrontation between managerial and union organizations ${ }^{[22]}$. Likewise, worker cooperatives predominate in the framework of greater development of industrial democracy with a significant implementation of share ownership plans ${ }^{[30]}$.

Nevertheless, this does not mean that in large Spanish companies there have not also developed systems for promoting greater direct participation from employees. It is true that indirect participation systems continue to have a great influence in our country (and we hope that they will continue to do so for a long time to come). However, it is not less certain that there exists a very significant proportion of companies which have decided to adopt new HRM practices, as can be deduced from the research which we have carried out. However, in the majority of the cases they do not reach the magnitude which these programs have reached in American companies.

For participation in decision-making, the order of the programs in both countries is very similar. In the first positions are suggestion systems, job enrichment or redesign, quality circles and other employee participation groups, while in the last positions we find employee committees in strategy matters, self-managing work teams and minibusiness units. The only exceptions are the survey feedback and union-management committees. The former is widely used in the United States while in Spain it only has intermediate use. Indirect participation through union representatives in Spain is one of the procedures which covers the greatest number of workers, while in the United States it is the least used. Although the order of importance is similar, the percentage of employees affected by each program is greater in the United States than in Spain. In some cases the coverage of the program in the United States is almost double that of Spain, while in other cases it is a third higher. The exception is the quality circles, that we did not expect, and union management committees.

Conversely, for financial participation, Spanish and American companies show an almost opposite behavior. The most used programs in the United States are those which are least used in Spain and vice versa. While in Spain fixed salary and employment security predominate, American companies use a greater amount of salary complements or indirect payments (non-monetary recognition awards, stock option plans and flexible benefits) with a much greater proportion of employees. The only thing that shows a certain similarity in both countries, contrarily to the expectations, is the use of gainsharing plans (possibly on account of its implantation jointly with quality circles and other participation groups). In conclusion, we may highlight that the behavior of the companies in both countries is different according to the nature of the participation, with greater proximity for participation in decision-making and considerably greater distance in financial participation.

It seems that the greater development of direct participation throughout all of Europe has come about not for promoting a greater social integration or for better serving human needs or for producing results from the legal directives developed by the EU, but rather for the need to achieve greater efficiency, flexibility and quality in work, in part due to new technological changes ${ }^{[11]}$. This new promotion of direct participation schemes does not necessarily attempt to weaken the representation systems of employees and the influence of their union organizations, as if often the case in American management strategies in the opinion of Knudsen ${ }^{[22]}$, but rather in some countries there has been a tendency toward mutual reinforcement (for example what has occurred in Germany and Denmark). Therefore, there is a greater and greater necessity to achieve the most competitive costs, produce high quality products and services, have constant innovation and more quickly react and deal 
with a more varied work force for jobs in which the use of knowledge is more and more important. This may lead to a greater participative model of development throughout the world in the future ${ }^{[16]}$.

Nevertheless, we cannot say anything for sure regarding future evolution. As we have seen from the temporary comparison with the series of American years, the differences between both countries tend to remain as time goes on. We hope that new forms of work organization and employee participation will continue to be developed in the future. This is an idea which is defended even by some of the authors whose researches have served to point out the differences more than the similarities between countries. This is the case for Gill and Krieger ${ }^{[11]}$, who concluded in their article: "despite the wide variations from one country to another, the survey results suggest that participation levels are likely to increase throughout the European Community in the future". Also, Knudsen ${ }^{[22]}$ stated that although the data are very incomplete, it seems safe to conclude that since the beginning of the 1980s there has been an increase in such forms of direct employee involvement in the four countries studied, even Spain. This development has taken place at company level and almost exclusively at the initiative management. With regard to this idea, according to Sisson ${ }^{[33]}$, one of the main problems to solve in promoting direct participation regardless of the country of origin is that the managerial organization hierarchy does not want to abandon the traditional forms of work organization. And so, future research must take this into account to analyze this phenomenon (see, for instance [26], for the important role of the human resource practitioner in the adoption of HRM practices; or [25], which analyzes the factors that influence the adoption by Spanish manufacturing firms of profit sharing schemes).

Whether this happens in Spain is still to be seen. We may suppose that, with its own particularities, Spain follows the international tendency. Our intention is to repeat this study in the future in our country, if we receive the backing of the international scientific community. With this we will be able to have greater information which can be used to better evaluate what changes have come about and how they can be explained. It is a shame that previous data regarding Spain do not exist, despite those which we have mentioned in this article; they would have allowed us to have a more general perspective regarding the evolution of employee participation in Spain. Consequently, this study has come to be a starting point, a base line from which we can continue offering some answers to the questions posed (in the same sense stated by Osterman ${ }^{[29]}$, to describe the American situation at that time).

We must not forget that the direct participation schemes in our country are relatively recent and were introduced into a system of conflictive labor relations and forms of traditionally authoritarian management. It is a question of time, as has occurred in other spheres of our political, social and cultural life, that the situation comes to change. So that, using the words of Juan Jos Castillo ${ }^{[4]}$, the new forms of work organization do not become old challenges in our time.

\section{References}

[1] The promotion of employee participation in profits and enterprise results, social europe supplement 3/91. in: PEPPER Report, European Foundation for the Improvement of Living and Working Conditions, Luxembourg, 1991.

[2] Promotion of participation by employed persons in profits and enterprise results (including equity participation) in member states. in: PEPPER II Report, European Foundation for the Improvement of Living and Working Conditions, Luxembourg, 1996.

[3] New forms of work organisation: Can europe realise its potential? results of a survey of direct employee participation in europe. EPOC Research Group, 1997. Luxembourg: European Foundation for the Improvement of Living and Working Conditions.

[4] J. J. Castillo. Las nuevas formas de organizacion del trabajo. Ministerio de Trabajo y Seguridad Social, Madrid, 1991.

[5] G. Cheney. Values at Work: Employee Participation Meets Market Pressure at Mondragon. Cornell University Press, Ithaca, 1999.

[6] R. W. Coye, J. A. Belohlav. An exploratory analysis of employee participation. Group \& Organization Management, 1995, 20(1): 4.

[7] C. Crouch, F. A. Heller. Organizational Democracy and Political Processes. International Yearbook of Organizational Democracy (vol. I), vol. 1. John Wiley \&Sons, London, 1983. 
[8] M. Escobar. Work Councils or Unions? University of Chicago Press, Chicago, 1995. In Works Councils. ed. Edited by Rogers and Streeck.

[9] D. Frhlich, C. Gill, H. Krieger. Roads to Participation in the European Community? Increasing Prospects of Employee Representative Involvement in Technological Change. European Foundation, Luxembourg, 1991.

[10] S. Gatley. Comparative Management: A Transcultural Odyssey. McGraw-Hill, London, 1996.

[11] C. Gill, H. Krieger. Participation in product and service quality: recent survey evidence from the european comunity. Total Quality Management, 1993, 4(3): 261-273.

[12] C. Hampden-Turner, F. Trompenaars. The Seven Cultures of Capitalism. Piatkus, London, 1993.

[13] IDE. Industrial Democracy in Europe. Clarendon Press, Oxford, 1981.

[14] IDE. Industrial Democracy in Europe Revisited. Oxford University Press, Oxford, 1993.

[15] E. E. L. III. High involvement Management. Jossey-Bass, San Francisco, 1991.

[16] E. E. L. III. La ventaja definitiva. Granica, Barcelona, 1996.

[17] E. E. L. III, S. Mohrman, G. Benson. Organizing for high performance: employee involvement, TQM, reengineering, and knowledge management in the fortune 1000. The CEO report. Jossey-Bass, San Francisco, 2001.

[18] E. E. L. III, S. Mohrman, G. . Ledford. Strategies for high performance organizations: employee involvement, TQM, and reengineering programs in fortune 1000 coporations. Jossey-Bass, San Francisco, 1998.

[19] E. E. L. III, S. A. Mohrman, G. E. Ledford. Employee involvement and total quality management: practices and results in Fortune 1000 companies. Jossey-Bass, San Francisco, 1992.

[20] E. E. L. III, S. A. Mohrman, G. E. Ledford. Creating high performance organizations: practices and results of employee involvement and total quality management in Fortune 1000 companies. Jossey-Bass, San Francisco CA, 1995.

[21] IPSE. Le Partage de Profit en Europe. Institutions et Effets Compares. Cahier Travail et Emploi, Paris, 1997.

[22] H. Knudsen. Employee participation in europe. Sage, London, 1995.

[23] C. J. Lammers, G. Szell. Organizational Democracy: Taking Stock. International Handbook of Participation in Organizations (vol. I). Oxforf University Press, Oxford, 1988.

[24] M. Marchington, A. Wilkinson, P. Ackers, J. Goodman. Understanding the meaning of participation: views from the work place. Human relations, 1994, 47(8): 867-894.

[25] A. B. Moriones, E. H. Arribas. Organisational incentive plans in spanish manufacturing industry. Personnel Review, 2002, 31(1/2): 128-142.

[26] G. D. Murphy, G. Southley. High performance work practices perceived determinants of adoption and the role of the hr practitioner. Personnel Review, 2003, 32(1): 73-92.

[27] OECD. Employment outlook. Paris, 1997. Organisation for Economic Co-operation and Development.

[28] OECD. Employment outlook. Paris, 1999. Organisation for Economic Co-operation and Development.

[29] P. Osterman. How common is workplace transformation and who adopts it? Industrial and Labor relations Review, 1994, 47(2): 173-188.

[30] E. Poutsma. Recent trends in employee financial participation in the european union. 2001. Dublin: European Foundation for the Improvement of Living and Working Conditions.

[31] V. Rus, R. Russell. Participation, Ownership and the Nature of Work. International Handbook of Participation in Organizations (vol. II). Oxford University Press, Oxford, 1989.

[32] A. Sagie, M. Koslowsky. Participation and empowerment in organizations. Modeling, efectiveness and aplication. SAGE, Thousand Oaks, 2003.

[33] K. Sisson. Se Mettre Daccord: Idees et Practiques. European Foundation, Luxembourg, 1996.

[34] K. Sisson. Direct participation and the modernisation of work organisation. European Foundation for the Improvement of Living and Working Conditions, 2000.

[35] R. N. Stern, S. McCarthy. The Organizational Practice of Democracy. International Yearbook of Organizational Democracy (vol. III). John Wiley \& Sons, London, 1986.

[36] W. F. Whyte, K. K. Whyte. Making Mondragon: The Growth and Dynamics of the Worker Cooperative Complex, 2nd edn. ILR Press, New York:, 1992.

[37] B. Wilpert, A. Sorge. International Perspectives on Organizational Democracy. International Yearbook of Organizational Democracy. Vol. II. John Wiley \& Sons, London, 1984.

[38] W. Wyatt. Analisis de tendencias retributivas. Capital Humano, 1997, (98): 34-38.

Appendix (Adapted from Lawler, Mohrman, and Ledford, 1995, pp. 171-173)

PARTICIPATIVE (INVOLVEMENT) PRACTICES

1. Suggestion system: A program that elicits individual employee suggestions on improving work or the work environment.

2. Survey feedback: Use of employee attitude survey results, not simply as an employee opinion poll, but rather as part of a larger problem solving process in which survey data are used to encourage, structure, and 
measure the effectiveness of employee participation.

3. Job enrichment or redesign: Design of work that is intended to increase worker performance and job satisfaction by increasing skill variety, autonomy, significance and identity of the task, and performance feedback. 4. Quality circles: Structured type of employee participation groups in which groups of volunteers from a particular work area meet regularly to identify and suggest improvements to work-related problems. The goals of QCs are improved quality and productivity, there are no direct rewards for circle activity, group problem solving training is provided, and the groups' only power is to suggest changes to management.

5. Other employee participation groups: Any employee participation groups, such as task teams or employee work councils, that do not fall within the definitions of either self-managing work teams or quality circles.

6. Union-management committees: Joint union-management committees, usually existing at multiple organizational levels, alongside the established union and management relationships and collective bargaining committees. These committees usually are NOT prohibited from directly addressing contractual issues such as pay, and are charged with developing changes that improve both organizational performance and employee quality of work life.

7. SeIf-managing work teams: Also termed autonomous work groups, semi-autonomous work groups, selfregulating work teams, or simply work teams. The work group (in some cases, acting without a supervisor) is responsible for a whole product or service, and makes decisions about task assignments and work methods. The team may be responsible for its own support services (such as maintenance, purchasing, and quality control) and may perform certain personnel functions (such as hiring and firing team members and determining pay increases).

8. Minibusiness units: Relatively small, self-contained organizational units (perhaps smaller than the plant level) that produces its own product of service and operates in a decentralized, partly autonomous fashion as a small business.

9. Employee committees in strategy matters: Any group that includes non-management employees that is created to comment on, offer advice on, or determine major corporation policies and/or business strategies.

PAY/REWARD SYSTEMS

1. Fixed salary: Employees earn a fixed quantity per month, depending on the job they perform. They don't receive other incentives.

2. Knowledge/Skill based pay: An alternative to traditional job-based pay that sets pay levels based on how many skills employees have or how many jobs they potentially can do, not on the job they are currently holding. Also called pay for skills, pay for knowledge, and competency-based pay.

3. Individual incentives: Bonuses or other financial compensation tied to short-term or long-term individual performance.

4. Work group incentives: Bonuses or other financial compensation tied to short-term or long-term work group, permanent team, or temporary team performance.

5. Profit sharing: A bonus plan that shares some portion of corporation profits with employees. It does not include dividend sharing.

6. Gainsharing: These plans are based on a formula that shares some portion of gains in productivity, quality, cost effectiveness, or other performance indicators. The gains are shared in the form of bonuses with all employees in an organization (such as a plant). It typically includes a system of employee suggestion committees. It differs from profit sharing and an ESOP in that the basis of the formula is some set of local performance measures, not corporation profits. Examples include the Scanlon Plan, the Improshare Plan, the Rucker Plan, and various custom-designed plants.

7. Non-monetary recognition awards: Any non-monetary reward (including gifts, publicity, dinners, etc.) for individual or group performance.

8. Flexible benefits (cafeteria-style): A plan that gives employees choices in the types and amounts of various fringe benefits they receive.

9. Employment security: Corporation policy designed to prevent layoffs. 10. Stock option plans: A plan that gives employees the opportunity to purchase company stock at a previously established price. 